\title{
PROFESSOR SEM FRONTEIRAS: trabalhando o lúdico na Educação Infantil a partir de múltiplas linguagens de sentido
}

\author{
LILIANE AFONSO DE OLIVEIRA \\ Universidade Federal Rural da Amazônia (UFRA). Doutoranda em Comunicação, Linguagens e \\ Cultura (UFRA). Mestre em Comunicação, Linguagens e Cultura (UFRA). Graduada em Letras \\ (Português) pela Universidade da Amazônia. Professor Auxiliar I da Universidade Federal Rural da \\ Amazônia. ORCID: 000-0003-4581-9952. E-mail: liliane_afonso@yahoo.com.br.

\section{MARIA DO PERPÉTUO SOCORRO CARDOSO DA SILVA} \\ Universidade Estadual do Para (UEPA). Doutora em Semiótica e Linguística Geral \\ (USP/2002). Mestre em Letras/Linguística (UFPA/1997). Especialista em Língua Portuguesa \\ (UECE/1992). Graduada em Letras (UFPA/1983). Professor Titular e pesquisadora da UEPA. \\ ORCID: 0000-0002-2574-4183. E-mail: cardoso_socorro@yahoo.com.br.
}

\section{WANUBYA DO NASCIMENTO MORAES CAMPELO}

Universidade Federal Rural da Amazônia (UFRA). Doutoranda em Letras pela Universidade Federal do Pará. Mestre em Letras/Teoria Literária pela Universidade Federal do Pará. Graduada em Letras (Português) pela Universidade do Estado do Pará. Professora Assistente II da Universidade Federal Rural da Amazônia.

ORCID: 0000-0002-6557-0827. E-mail: wanubyacampelo@gmail.com.

\section{CÍNTIA MARIA CARDOSO}

Universidade Federal Rural da Amazônia (UFRA). Doutoranda em Educação pela Universidade de São Paulo. Mestre em Linguística Aplicada pela Universidade de Taubaté (2008). Licenciada em Letras (Habilitação em Língua Portuguesa) pela Universidade Federal do Pará e Pedagogia pela Universidade Cidade de São Paulo. Professora Assistente da Universidade Federal Rural da Amazônia (UFRA). ORCID: 0000-0002-6373-6803. E-mail: cintia.ufra@gmail.com. 


\section{PROFESSOR SEM FRONTEIRAS: trabalhando o lúdico na Educação Infantil a partir de múltiplas linguagens de sentido}

As múltiplas linguagens trabalhadas através do lúdico na educação infantil fortalecem o processo de desenvolvimento da aprendizagem da criança, no qual, cria e passa a usar seu imaginário para organizar os espaços sociais nos quais está inserida. Com o objetivo de ampliar reflexões sobre múltiplas linguagens podem ser trabalhadas no contexto da educação infantil, este estudo ancora-se à discussão de que o professor da educação infantil precisa repensar suas práticas com o apoio do lúdico. Caracteriza-se como um estudo exploratório, de aportes teóricos relacionados ao lúdico como subsídio essencial para o desenvolvimento infantil. A partir de conclusões preliminares admite-se que é um tema de extrema importância, pois, as múltiplas linguagens desenvolvidas no ambiente escolar reverberam ações pertinentes ao reconhecimento e desenvolvimento cognitivo da criança.

Palavras-chave: Linguagens. Lúdico. Educação Infantil.

\section{TEACHER WITHOUT FRONTIERS: working the lúdico in children education from multiple languages of sense}

The multiple languages worked through the ludic in early childhood education strengthens the process of developing the child's learning, in which he creates and uses his imagery to organize the social spaces to which he is inserted. With the aim of expanding reflections on how multiple languages can be worked out in the context of early childhood education, this study is anchored to the discussion that the preschool teacher needs to rethink his practices with the support of the ludic. It is characterized as an exploratory study of theoretical contributions related to play as an essential subsidy for child development. Based on preliminary conclusions, it is admitted that this is an extremely important topic, since the multiple languages developed in the school environment reverberate actions pertinent to the cognitive recognition and development of the child.

Keywords: Languages. Ludic. Child Education.

\section{PROFESOR SIN FRONTERAS: trabajando al jugador en la educación infantil desde múltiples idiomas sentidos}

Los múltiples idiomas trabajados a través del juego en el jardín de infantes fortalecen el proceso de desarrollo del aprendizaje del niño, en el cual él crea y comienza a usar su imaginación para organizar los espacios sociales en los que se inserta. Con el fin de ampliar las reflexiones sobre cómo se pueden trabajar múltiples idiomas en el contexto de la educación de la primera infancia, este estudio se basa en la discusión de que los maestros de la primera infancia deben repensar sus prácticas con el apoyo de lo lúdico. Se caracteriza por ser un estudio exploratorio de las contribuciones teóricas relacionadas con el juego como un subsidio esencial para el desarrollo infantil. Con base en conclusiones preliminares, se admite que este es un tema extremadamente importante, ya que los múltiples idiomas desarrollados en el entorno escolar repercuten en las acciones pertinentes para el reconocimiento y el desarrollo cognitivo del niño.

Palabras clave: Idiomas. Juguetón. Educación Infantil.

\section{plurais}

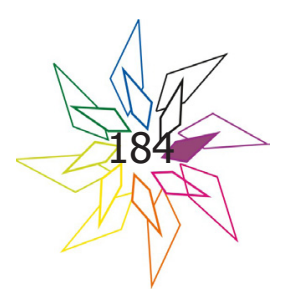




\section{PROFESSOR SEM FRONTEIRAS: a trabalhando o lúdico na Educação Infantil a partir de múltiplas linguagens de sentido}

\section{Introdução}

A linguagem é a maior responsável pelas atividades psíquicas dos processos cognitivos do ser humano. A identidade do indivíduo advém de uma construção cultural respeitando as peculiaridades e especificidades dos sujeitos e está vinculada à linguagem, algo que não é fixo e é construído a partir da interação.

A língua possibilita ao ser humano relacionar-se com o mundo. Por meio da língua, é possível transmitir pensamentos, ideias e interagir com seus pares (ALMEIDA; FONSECA, 2013). A vida do ser humano está intensamente ligada à comunicação.

Logo, língua e linguagem estão conectadas e é impossível pensar a vida sem elas, pois são dispositivos essenciais na vida humana. Assim, é assumida como constitutiva do sujeito, pois possibilita interações fundamentais para a construção do conhecimento (VIGOTSKI, 2001).

O papel socioeducativo da escola e do professor no processo de aprendizagem da criança deve ser de estímulo ao uso e importância do brinquedo na relação aprender, uma vez que através do brinquedo a criança consegue recriar sua realidade, interpretar suas ações, e trazer importantes significados para sua vivência.

Piaget (1998) avalia o brincar como a linguagem característica da criança por ter maior expressividade que a linguagem verbal. Esta razão leva-nos a reflexões acerca da formação do professor que atua na educação infantil, pois suas atividades influenciam o processo de aprendizagem da criança que trás para sala de aula o brincar como elemento da sua realidade.

Admite-se que é um tema de extrema valia, pois considera-se a importância de subsidiar discussões que fortalecem o uso do lúdico nas múltiplas linguagens da educação infantil como fator positivo no processo de ensino e aprendizagem, contribuindo para o interesse de outros pesquisadores em dar continuidade a pesquisas sobre o tema.

O papel do professor da educação infantil é de constante estímulo do processo de construção do conhecimento dos educandos. O aluno é despertado para a criticidade de forma que almeja-se, no futuro, 
lutar pelos seus interesses em meio à sociedade. O professor além de educador atua como mediador para a construção do conhecimento. O aluno aprenderá a "pensar" e a questionar por si mesmo e, não mais receber passivamente as informações como se fosse um depósito deste educador.

A realização deste estudo procura dialogar com as realidades vividas dentro das salas de aula e como este profissional da educação infantil estão preparando os seus alunos a uma aprendizagem de qualidade e dinâmica. Sabe-se que os docentes buscam em suas práticas diárias formações complementares para a atuação diferenciada no trabalho, mas há também o acúmulo de funções que fora dado a este profissional, estimulando-o a cooperação e a valorização individual e da escola que diminuem os passos desse constante aperfeiçoamento.

Silva (1991, p. 03) ao abordar sobre métodos para ser um bom professor alerta para:

Atualize-se, atualize-se, atualize-se... - esta repetição é intencional e pretende apagar da sua consciência algum possível resquício de desejo de acomodação. A chamada "educação permanente" é fundamental para todos os indivíduos e mais fundamental ainda para os educadores. Além de uma dedicação maior à literatura de sua área específica de atuação, procure acompanhar e inter-relacionar os dados provindos de outros campos do conhecimento, principalmente história, política e economia. É o conhecimento da totalidade do real que aumenta o seu poder de julgamento e decisão. E os maiores beneficiados serão você mesmo e os seus alunos.

Nesse sentido, a capacitação do professor deve ser um processo contínuo, para ampliar o seu conhecimento, a fim de, garantir uma evolução no seu potencial, sua autonomia didática e o seu comprometimento com a educação.

Os profissionais da educação infantil precisam manter um comportamento ético com as crianças educadas, não permitindo que estas sejam expostas a situações constrangedoras. Dessa forma, o lúdico como metodologia pedagógica na educação infantil tem contribuído de forma positiva para o desempenho deste papel.

\section{A evolução do homem na sociedade e as alterações de sentido da infância}

A preocupação com a infância não é um assunto novo e o termo historicamente já sofreu alterações de sentido.

\section{plurais}

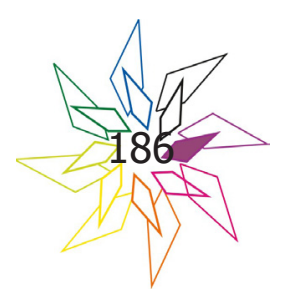


$\mathrm{O}$ atendimento à criança de zero a seis anos iniciou com a chegada dos jesuítas que investiram nos pequenos indiozinhos, filhos de gentios, que junto como os órfãos portugueses vindos da metrópole, recebiam uma formação evidenciada pela exaltação na fé, da religiosidade e das qualidades individuais (COSTA E VAREJÃO, 1997, p. 11).

Destarte, os autores abordam que no Brasil, no período colonial, pouco se fez pela infância. Ao regressarmos à história e à evolução do homem na sociedade, percebe-se que a criança nem sempre foi ponderada como é hoje.

Outrora, a criança era considerada como miniatura do adulto. Quando nascidas ou criadas por classes altas eram educadas para o futuro, quando provindas de classes baixas seu valor era relativo à sua utilidade servil, agregada à geração da renda da sua família.

Observa-se que no Brasil a exploração na infância pelo trabalho remonta o período da colonização. Inclusive, antes de estabelecidas as relações entre os grupos aqui existentes e o branco colonizador, as caravelas portuguesas já traziam no século XVI crianças trabalhadoras, fato que é constatado ao longo da história.

De acordo com a história, a primeira medida legal efetiva no Brasil que protegia o trabalho de crianças e adolescentes foi o Decreto 17.943-A, de 12 de outubro de 1927, que proibia o trabalho aos que estivessem na faixa etária inferior a doze anos, posteriormente, a partir de 1932, ampliada para quatorze anos. Assim, reconhece-se que as crianças no Brasil, desde a colonização foram privadas do direito de estudar e brincar.

Fortuna (2011) corrobora que a criança ao brincar desenvolve sua imaginação e a criatividade durante a infância, apontada como período de extrema importância na vida dos seres humanos.

A brincadeira, a partir do jogo, da adivinhação, entre outros, faz parte da cultura de um povo e marca contextos históricos que o homem vive. Conforme Kishimoto (1993) a cultura do brincar no Brasil sofreu forte influência dos povos colonizadores, que trouxeram jogos como os de saquinhos, a bolinha de gude, o jogo de botão, o pião, entre outros. Os negros igualmente emprestaram suas brincadeiras como o quente e o frio e, o chicotinho queimado. Os índios transmitiram o gosto pela imitação dos animais. Foram brincadeiras que permearam e ainda são vivas em algumas regiões do Brasil.

\section{plurais}


A criança expressa-se pelo ato lúdico e é através desse ato que a infância carrega consigo as brincadeiras. Elas perpetuam e renovam a cultura infantil, desenvolvendo formas de convivência social, modificando-se e recebendo novos conteúdos, a fim de renovar a cada nova geração (CRAIDY, KAERCHER, 2001, p.103).

Nas práticas educacionais com a educação infantil devem-se criar atividades significativas que estimulem as múltiplas linguagens, despertando a criatividade, a linguagem oral, momentos imaginários e a criatividade das crianças.

Recorrendo a Freire (1999, p. 97) quando aduz que:

Não posso entender os homens e as mulheres, a não ser mais do que simplesmente vivendo, histórico, cultural e socialmente existindo como seres fazedores do seu caminho que, ao fazê-lo se expõem ou se entregam aos "caminhos" que estão fazendo e que assim os refazem também.

Destarte, no saber freireano (1999) o educador da educação infantil precisa estar em permanente processo de educação. Não podendo não se sensibilizar nas mudanças e permanecer em ações docentes reprodutivas. Talvez, o fato de não se sentirem preparados para autocrítica do seu conhecimento, não possibilita estabelecer um referencial verdadeiro de suas falhas e incoerência decorrentes de sua formação.

A legislação brasileira reconhece a necessidade de traçar diretrizes ao sistema educacional a partir da Constituição de 1934 que posteriormente em 1961 acarretou a promulgação da Lei de Diretrizes e Bases - LDB; Lei no 4.024 que institui ao Estado essa função.

Em 1996, resultado de longos debates que duraram cerca de oito anos (1988-1996) a LDB é reformulada sob a Lei $n^{\circ} 9.394$ que estabelece as diretrizes e bases da educação nacional, tendo uma seção específica sobre a educação infantil ainda apontando para formação de docentes para atuar na educação básica o nível superior, em curso de licenciatura, de graduação plena, em universidades e institutos superiores de educação, admitida, como formação mínima para o exercício do magistério na educação infantil e nas quatro primeiras séries do ensino fundamental, a oferecida em nível médio, na modalidade Normal.

A constituição da LDB é um passo importante para a educação. Em especial, no seu Artigo 29, discorre que a educação infantil é a primeira etapa da educação básica, e tem como finalida-

\section{plurais}


de o desenvolvimento integral da criança até os seis anos de idade, em aspectos físicos, psicológico, intelectual e social.

Aduz ainda que a educação infantil é um complemento da ação da família e da comunidade e em seu o Art. 30 ressalta que a educação infantil será oferecida em "I- creches ou entidades equivalentes, para crianças de até três anos de idade; II- pré-escolas para crianças de quatro anos de idade" (BRASIL, 1996).

A expressão “educação infantil” é um direito reconhecido por Lei, considerada como uma etapa primordial na vida da criança que marca o início de seu desenvolvimento, representando um marco histórico de grande importância para a educação infantil no país.

\section{As Múltiplas Linguagens na Educação Infantil: promoção de experiências intera- tivas no espaço escolar}

O professor da educação infantil na sala de aula é incentivador de produções individuais ou em grupo capazes de estimular o olhar crítico das crianças às produções por elas realizadas despertando no ensino a curiosidade, através das brincadeiras que utilizadas de forma inovadora e lúdica poderão envolver outras instituições extra muros da escola, como a família, a comunidade, a ponto de mobilizá-los a práticas de conscientização dos recursos hídricos, preservação da natureza, assuntos de suma importância para educação da criança, pois, percebe-se o quanto é difícil unificá-los de forma interdisciplinar.

O termo "linguagem" geralmente aparece associado apenas à linguagem verbal e escrita, que, ganha notoriedade a ponto de dificultar a curiosidade da criança nas escolas por outras manifestações. Conhecer e explorar as linguagens que as crianças utilizam para se expressar depende do "estar junto com elas", percebendo assim, características próprias dessa criança de acordo com sua faixa etária, gênero ou classe social.

Refletir acerca das múltiplas linguagens na educação infantil permeia a promoção de experiências interativas no espaço escolar com meninos e meninas a partir das artes plásticas, fotografia, teatro, poesia, momentos de literatura regional, música, cinema, entre outras que deem sentido ao processo de aprendizagem da criança. É importante o papel da família, da escola e dos educadores da educação infantil, no sentido de possibilitarem espaços de criação dessas linguagens.

Crianças, meninos e meninas, são sujeitos constituídos de história e de direitos que experimentam a partir das suas brincadeiras, individuais ou coletivas, diferentes sentidos e culturas por meio das 
linguagens, que posteriormente materializam suas opiniões, expondo suas curiosidades sobre o mundo, desde questões históricas às sociais.

As crianças na educação infantil nos possibilitam a reflexão de que os saberes estão além das linguagens verbais ou escritas. Ao se expressarem, utilizam múltiplas formas de linguagens, como pinturas, desenhos, canto, dança e afins.

Profissionais das escolas infantis, em algumas situações, no intuito de querer que as crianças sejam a eles obedientes, despertam sentimentos de insegurança nas crianças, deixando-as desamparadas, com temor em relação ao educador, não estabelecendo confiança. Ao educador deve-se o papel de propiciar esses elementos, que favoreçam a criatividade das crianças, estabelecendo o respeito.

Almeida (1987, p. 195) profere que a "esperança de uma criança, ao caminhar para a escola é encontrar um amigo, um guia, um animador, um líder - alguém muito consciente e que se preocupe com ela e que a faça pensar, tomar consciência de si de do mundo". A esperança desta criança está na proposta de atividades lúdicas educativas diferenciadas que serão trabalhadas no desenvolvimento do seu cognitivo e vão contribuir para que esta criança construa uma sociedade melhor.

Os educadores ao trabalharem o lúdico nas múltiplas linguagens de sentido transformam o brincar em atividade pedagógica. Experimentam como interlocutores deste processo o verdadeiro significado da aprendizagem: o prazer em aprender. As crianças não querem ser apenas dotadas de conteúdos por elas assimilados muitas vezes por exercícios mecânicos e repetitivos.

Por isso, formação contínua de educadores é de suma importância, pois possibilita contato com métodos e experiências novas. Freire (1999, p. 42), contribui que "na formação permanente dos professores, o momento fundamental é o da reflexão crítica sobre a prática". Contudo, melhora-se a prática futura refletindo criticamente nossas práticas atuais.

Diante desse pensamento, percebemos que a formação do professor é outro fator que exerce influência no processo de ensino. Nessa perspectiva, para Freire (1999) o professor, como mediador no processo de aprendizagem, considera importante que este, esteja sempre buscando o aperfeiçoamento de seus conhecimentos administrando sua própria formação, haja vista que as teorias e saberes adquiridos durante a universidade precisam fundamentar suas práticas educativas, de modo que teoria e prática precisem andar simultaneamente para que de fato a aprendizagem seja significativa e o professor assuma seu papel nesse processo.

\section{plupais}

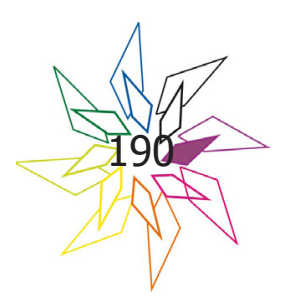




\section{Pensamento e linguagem: propostas lúdicas pedagógicas na Educação Infantil}

Vygotsky (1984) ao se aprofundar na relação entre o pensamento e a linguagem chegou à conclusão de que "a verdadeira trajetória de desenvolvimento do pensamento não vai ao sentido do pensamento individual para o socializado, mas do pensamento socializado para o individual” (VYGOTSKY, 1984).

Esta afirmação permitiu a Vygotsky (1984) entender que o pensamento não é desenvolvido com autonomia e independência, mas a partir de condições determinadas, sob a mediação dos signos e dos instrumentos culturais que se apresentam histórica e socialmente disponíveis. Assim, propôs o conceito inovador de Zona de Desenvolvimento Proximal (ZDP), que corresponde à,

Distância entre o nível de desenvolvimento real, que se costuma determinar através da solução independente de problemas, e o nível de desenvolvimento potencial, determinado através da solução de problemas sob a orientação de um adulto ou em colaboração com companheiros mais capazes (VYGOTSKY, 1984, p. 97).

Assim, é na ZDP que deve atuar o professor da educação infantil, colaborando para o amadurecimento cognitivo destes alunos. Não apenas submetendo o aluno a condições ideais de ensino. A atividade docente na educação infantil é uma prática social complexa.

Tardif (2006) pontua a importância da relação harmoniosa que deve se ter entre professor e aluno, uma vez que tal relação contribui positivamente para o favorecimento do processo de ensino e aprendizagem. $\mathrm{O}$ autor enfatiza ainda que este relacionamento de se dá por meio de relações de respeito, carinho, amor, amizade, entre outros.

As manifestações de linguagem das crianças convidam-nos a repensar o mundo, mediados pelos corpos que se balançam e expressam as diversidades de sentidos criados a partir de interações sociais. Corpos que falam com sons, letras, gestos, balbucios. A criança se constitui quando institui estas interações com o meio e vive situações diferenciadas de representação.

O profissional da educação infantil precisa conhecer as crianças que convivem durante sua prática profissional, buscando novos métodos que auxiliem e melhorem o processo de ensino-aprendizagem dessas crianças. Se o professor for um bom observador, capaz de descobrir quem são elas, quem são seus familiares, as músicas que ouvem, o que gostam de dançar, as histórias contadas por eles, os acontecimentos do bairro em que a escola está situada, as informações sob seus vários ângulos, verificará que muitos conteúdos de um livro didático podem não condizer com sua vida real e a de seus alunos. 
O lúdico auxilia a aprendizagem da criança na educação infantil. Entretanto, isso não significa que possuir um espaço lúdico seja o suficiente, permitindo que o ambiente da sala de aula se torne desorganizado ou de bagunça; mas que este espaço deve somar-se a um ambiente de estratégias direcionadas pelo professor às crianças com determinado foco, procurando atribuir novo significado ao processo de ensino e aprendizagem.

Em relação ao papel do lúdico nas atividades didáticas, Machado (1995, p. 40) argumenta que:

Quando se considera o papel do lúdico nas atividades didáticas, as dimensões lúdicas (em sentido restrito) e utilitárias (o lúdico servem para introduzir certos temas) se destacam. A primeira refere-se ao divertimento e a brincadeira, enquanto que a segunda trata dos resultados educativos a serem alcançados propriamente ditos (MACHADO, 1995, p. 40).

Logo, qualquer que seja a atividade lúdica trabalhada existe outras dimensões que podem transcender o lúdico em si, para um campo metafórico, que podem estar associadas a outras significações que precisarão ser mais explorada pelos educadores através de jogos, danças, brincadeiras ou outro conjunto de atividades educativas, realizadas na escola ou fora dela.

Conforme os Parâmetros Curriculares Nacional - PCN's para a Educação Infantil, “as atividades lúdicas, através das brincadeiras favorecem a autoestima das crianças ajudando-as a superar progressivamente suas aquisições de forma criativa" (BRASIL, 1998, p. 27).

As brincadeiras exercem papel importante para o desenvolvimento integral da criança. Por meio das brincadeiras a criança amplia seus conhecimentos e expressa a partir da sua espontaneidade no brincar impressões constituídas socialmente dentro do seu campo familiar e social. Neste sentido, os PCN's (1998 p.28) aduzem que:

As brincadeiras de faz-de-conta, os jogos de construção e aqueles que possuem regras, como os jogos de sociedade (também chamados de jogos de tabuleiro) jogos tradicionais, didáticos, corporais, etc., propiciam a ampliação dos conhecimentos da criança por meio da atividade lúdica.

É possível, através do brincar a criança adquirir sentidos como de responsabilidades, respeito, amizade e perceber que dentro da sociedade em que esta inserida há diversos grupos e culturas diferentes, estimulando assim seu intelecto e suas potencialidades. A brincadeira também proporciona

\section{plurais}

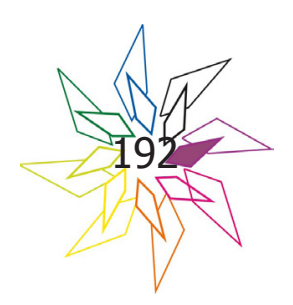


a movimentação do corpo da criança estimulando, assim, seu desenvolvimento corporal, que nessa fase é muito importante.

De acordo com as Diretrizes Curriculares Nacionais para a Educação Infantil (BRASIL, 2009, p. 04) as práticas pedagógicas da Educação Infantil devem possuir eixos do currículo norteadores as interações e a brincadeira, garantindo experiências que:

Promovam o conhecimento de si e do mundo por meio da ampliação de experiências sensoriais, expressivas, corporais que possibilitem movimentação ampla, expressão da individualidade e respeito pelos ritmos e desejos da criança;

Favoreçam a imersão das crianças nas diferentes linguagens e o progressivo domínio por elas de vários gêneros e formas de expressão: gestual, verbal, plástica, dramática e musical;

Possibilitem às crianças experiências de narrativas, de apreciação e interação com a linguagem oral e escrita, e convívio com diferentes suportes e gêneros textuais orais e escritos;

Recriem, em contextos significativos para as crianças, relações quantitativas, medidas, formas e orientações espaço temporais;

Ampliem a confiança e a participação das crianças nas atividades individuais e coletivas;

Possibilitem situações de aprendizagem mediadas para a elaboração da autonomia das crianças nas ações de cuidado pessoal, auto-organização, saúde e bem-estar;

Possibilitem vivências éticas e estéticas com outras crianças e grupos culturais, que alarguem seus padrões de referência e de identidades no diálogo e conhecimento da diversidade;

Incentivem a curiosidade, a exploração, o encantamento, o questionamento, a indagação e o conhecimento das crianças em relação ao mundo físico e social, ao tempo e à natureza;

Promovam o relacionamento e a interação das crianças com diversificadas manifestações de música, artes plásticas e gráficas, cinema, fotografia, dança, teatro, poesia e literatura;

Promovam a interação, o cuidado, a preservação e o conhecimento da biodiversidade e da sustentabilidade da vida na Terra, assim como o não desperdício dos recursos naturais;

Propiciem a interação e o conhecimento pelas crianças das manifestações e tradições culturais brasileiras;

Possibilitem a utilização de gravadores, projetores, computadores, máquinas fotográficas, e outros recursos tecnológicos e midiáticos. (BRASIL, 2009, p. 04) 
Dessa forma, os objetivos da proposta pedagógica das instituições de Educação Infantil devem ter como objetivo garantir à criança o acesso a processos de apropriação, renovação e articulação de conhecimentos e aprendizagens de diferentes linguagens, assim como o direito à proteção, à saúde, à liberdade, à confiança, ao respeito, à dignidade, à brincadeira, à convivência e à interação com outras crianças. As múltiplas linguagens de meninos e meninas no cotidiano das creches e pré-escolas, em suas elaborações da proposta curricular, de acordo com suas características, identidade institucional, escolhas coletivas e particularidades pedagógicas, estabelecerão modos de integração dessas experiências

A atividade recreativa é reconhecida como meio de fornecer múltiplas linguagens de sentido a criança a partir de um ambiente agradável, planejado e motivador que possibilite a aprendizagem. Nesse contexto, a brincadeira ganha um escopo ideal no processo de aprendizagem da criança, pois estimula o interesse do aluno.

Para o professor estimular uma aula, faz-se necessário vivenciar, ele mesmo, esta experiência, inovando-o, planejando tempo e espaço para proveito dos alunos, explorando técnicas já utilizadas e criando outras, lendo teorias, confrontando-as com a prática, observando experimentos com outros educadores, ampliando seu universo de conhecimento e sensibilidade.

\title{
O brincar e o desenvolvimento da criança na Educação Infantil
}

Para Vygotsky (1984) é por meio da brincadeira que a criança reproduz o discurso externo e o internaliza, construindo assim seu próprio pensamento. A criança possui sua identidade, vinculada à linguagem que para Vygotsky (1984) tem importante papel no desenvolvimento cognitivo da criança à medida que sistematiza suas experiências e ainda colabora na organização dos processos em andamento. Para o autor:

\begin{abstract}
A brincadeira cria para as crianças uma "zona de desenvolvimento proximal" que não é outra coisa senão a distância entre o nível atual de desenvolvimento, determinado pela capacidade de resolver independentemente um problema, e o nível atual de desenvolvimento potencial, determinado através da resolução de um problema sob a orientação de um adulto ou com a colaboração de um companheiro mais capaz. (VYGOTSKY, 1984, p. 97)
\end{abstract}

As atividades lúdicas reproduzem situações vividas no cotidiano das crianças. O educador ao fazer uso de brincadeiras, histórias, jogos educativo direcionado a resolução de problemas faz com que a criança sinta-se desafiada, estimulando-a a pensar e resolver situações problemáticas, para que transcreva ou recrie princípios utilizados pelo adulto.

\section{plurais}


O ato de brincar facilita a comunicação, possibilitando a construção da criticidade, da autonomia e da capacidade criadora, estabelecendo, uma relação entre jogos/brincadeiras e aprendizagem.

Para Vigotsky (1979, p. 45) "a criança aprende muito ao brincar, o que aparentemente ela faz apenas para distrair-se ou gastar energia é na realidade uma importante ferramenta para o seu desenvolvimento cognitivo, emocional, social, psicológico". Assim como é importante a brincadeira no processo de aprendizagem da criança, também é importante o respeito a esta quando esta brincando, pois o mundo da criança é instável e oscila entre realidade e fantasia.

A afinidade da brincadeira infantil com a natureza da própria criança tem reconhecimento histórico, por isso, vem sendo tema de inúmeras pesquisas e estudos ao longo dos anos. É interessante destacar que em todas as concepções teóricas sobre o desenvolvimento e educação da criança pequena e na literatura em geral, a brincadeira aparece como um importante recurso na construção de conhecimentos e desenvolvimento integral. A brincadeira é a atividade que faz parte do cotidiano de qualquer criança, independente do local onde vive, dos recursos disponíveis, do grupo social e da cultura da qual faça parte, todas as crianças brincam (PEDROSO et.al., 2011, p.01).

Através do brincar, as crianças dão o melhor de si: pensam, planejam, observam o erro, torcem, comemoram; todo esse interesse dos pequenos faz dele um valioso recurso, que pode ser incluído nas aulas para que possam ter melhor compreensão de mundo, além de ter maior desenvolvimento integral nos aspectos social, físico, emocional, afetivo, ou seja, o ato de brincar além de favorecer estímulo, é uma importante forma de comunicação, faz parte da vivência infantil e ainda, seu aprendizado pode ocorrer de forma mais prazerosa.

A criança é um ser social que se desenvolve entre outros seres humanos, no espaço e tempo determinados. Seu desenvolvimento é sequencial e caminha de estruturas mais simples para estruturas mais complexas, portanto, "é uma equilibração progressiva, uma passagem contínua de um estado de menor equilíbrio para um estado de equilíbrio maior" (PIAGET, 1980, p. 11).

Piaget (1980) analisou o desenvolvimento do pensamento, compreendendo o período do nascimento até a adolescência. Para o autor, a inteligência tem sua estrutura biológica com a funcionalidade de adaptar o organismo às exigências do meio.

O ato de brincar contribui, para interiorização de determinados modelos de adulto, no âmbito de grupos sociais diversos. "Conceber a criança como o ser social que ela é significa considerar que ela 
tem uma história; que pertence a uma classe social determinada" (PASCHOAL e MACHADO, 2007, p. 57). A brincadeira compreende relações voltadas ao seu contexto da origem. Nas brincadeiras, as crianças transformam os conhecimentos já internalizados em algo mais sólido, referente à sua realidade ou vividas pelo seu grupo familiar ou social. Brincando a criança relaciona o sentido do papel assumido na brincadeira com outros papéis, tornando-a madura para ter consciência destes em outras situações.

Assim, compreende-se que a oportunidade de criarem ou vivenciarem brincadeiras ligadas ao imaginário faz com que as crianças organizem seu processo de pensamento.

As crianças podem acionar seus pensamentos para resolução de problemas que lhe são importantes e significativos. É importante que tenhamos claro que quanto mais a criança brinca, mais é levada a organizar e a reorganizar os seus processos de pensamento, ao mesmo tempo em que conquista as mudanças qualitativas mais significativas em sua personalidade. (PASCHOAL E MACHADO, 2007, p. 55)

Para que esse exercício de criação tenha uma riqueza de experiências à aprendizagem direta da criança é necessário aproximar-se da realidade desta criança para ajudá-la a partir da articulação entre o imaginário e a reprodução da realidade atribuir a partir de múltiplas linguagens novos sentidos.

O lúdico fortalece a autoestima de crianças na educação infantil, fazendo com que consigam, de forma evolutiva, avançar em seus processos de aquisição, de forma criativa. Ao propiciar a brincadeira, cria-se um ambiente para que as crianças possam experienciar o mundo a partir da linguagem. A ludicidade apoia-se na forma como os profissionais da educação desenvolvem a criatividade, os conhecimentos das crianças através dos jogos, músicas ou danças.

\section{Considerações Finais}

O professor tem papel importante na educação infantil de promover o ensino de maneira dinâmica, criativa, buscando estratégias que mantenham vivo o interesse do conhecimento às crianças. $\mathrm{O}$ lúdico naEducação Infantil proporciona divertimentos noato de ensinar e aprender.

Portanto, o professor da educação infantil deve valorizar o lúdico contribuindo assim para o desenvolvimento infantil, uma vez que a brincadeira acompanha a progresso da inteligência e do pensamento, desenvolvimentos indispensáveis ao equilíbrio afetivo e intelectual da criança.

Olúdico ajuda acriança aconstruir novas descobertas, enriquecendo sua personalidade. Simboliza uma ferramenta pedagógica que conduz ao professor a condição de estimulador da aprendizagem.

\section{plupais}

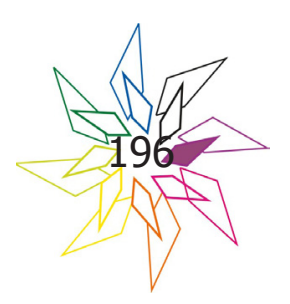


Neste contexto, este estudo conseguiu alcançar em suas discussões alicerçadas nos teóricos que o brincar no processo educacional é significativo ao desenvolvimento infantil. É válido ressaltar que convivemos em um período que as tecnologias avançam de forma efêmera, inclusive no contexto educacional. Ressalta-se que as atividades lúdicas não devem ser perdidas no contexto da escola, principalmente na educação infantil, uma vez que comprovadamente a partir de experimentos e referências teóricas é uma ferramenta atraente e educativa que auxilia no desenvolvimento da criança.

Assim, conclui-se que a ludicidade é a forma como os profissionais da educação desenvolvem a criatividade, os conhecimentos das crianças, através dos jogos, músicas ou danças. Percebe-se que o intuito a ser alcançado pelos profissionais é educar, ensinar, se divertindo e interagindo com os outros. O lúdico está nas atividades que despertam o prazer nas crianças. Atividades como jogos, pega-pega, dança, entre outras, precisam ser lúdicas, fazendo com que a criança inicie a aprendizagem sobre o mundo e sobre si mesma.

O educador deve sempre buscar uma formação contínua a fim de, garantir uma evolução no seu potencial, sua autonomia didática e o seu comprometimento com a educação, desenvolvendo atividades lúdicas inovadoras que proporcionem o interesse das crianças. O brincar na educação infantil propicia que as crianças aprendam de forma prazerosa, contribuindo para que construam uma sociedade melhor.

\section{REFERÊNCIAS}

ALMEIDA, Andréia Oliveira; FONSECA, Maria da Conceição Vinciprova. Libras: a inclusão de surdos na escola regular. Revista Práxis (Online), v. 5, p. 65-69, 2013.

ALMEIDA, P. (1987). Educação Lúdica - técnicas e jogos pedagógicos. São Paulo: Edições Loyola.

BRASIL. Constituição da República dos Estados Unidos do Brasil, de 16 de Julho de 1934. Rio de Janeiro: Presidência da República, 1934. Disponível em: http://www.planalto.gov.br/ccivil_03/constituicao/constituicao34.htm. Acesso em: 25 jun. 2020.

BRASIL. Decreto no 17.943-A, de 12 de outubro de 1927. Consolida as leis de assistencia e protecção a menores. Rio de Janeiro: Presidência da República, 1927. Disponível em: http://www. planalto.gov.br/ccivil_03/decreto/1910-1929/D17943Aimpressao.htm. Acesso em: 3 jul. 2020.

BRASIL. Lei n 4.024, de 20 de dezembro de 1961. Fixa as Diretrizes e Bases da Educação Nacional. Brasília, DF: Presidência da República 1961. Disponível em: https://www.planalto.gov.br/ ccivil_03/Leis/L4024.htm. Acesso em: 25 jun. 2020. 
BRASIL. Lei $\mathbf{n}^{0}$ 9.394, de 20 de dezembro de 1996. Estabelece as diretrizes e bases da educação nacional. Brasília, DF: Presidência da República, 1996. Disponível em: http://www.planalto.gov. br/ccivil_03/leis/19394.htm. Acesso em: 20 jun. 2020.

BRASIL. Ministério da Educação. Conselho Nacional de Educação. Câmara de Educação Básica. Resolução $\mathbf{n}^{\circ}$ 5, de 17 de dezembro de 2009. Fixa as Diretrizes Curriculares Nacionais para a Educação Infantil. Brasília, DF: MEC, 2009.

BRASIL. Ministério da Educação e do Desporto. Secretaria de Educação Fundamental. Parâmetros curriculares nacionais. Brasília, DF: MEC/SEF, 1998.

COSTA, Adalvo da Paixão \& VAREJAO, Ana Maria Louzada. Educação infantil: uma contextualização histórica. Pró-discente. Caderno de Produção Acadêmico Científica do Programa de Pós-Graduação em Educação. Universidade Federal do Espírito Santo. Vol. 3 n.6, 1997.

CRAIDY, Carmem Maria. KAERCHER, Gladys E.(Org.) Educação Infantil pra que te quero. Porto Alegre: Artmed Editora, 2001.

COSTA, Adalvo da Paixão; VAREJÃO, Ana Maria Louzada. Educação infantil: uma contextualização histórica. Caderno de Produção Acadêmico Científica do Programa de Pós-Graduação em Educação, Espírito Santo, v. 3 n. 6, 1997.

FORTUNA, Tânia Ramos. O Lugar do brincar na Educação Infantil. Revista Pátio Educação Infantil, Ano IX, n. 27, p. 08-10, abr.jun. 2011.

FREIRE, P. Pedagogia da autonomia: saberes necessários à prática educativa. 12 ed. São Paulo: Paz e Terra, 1999.

KISHIMOTO, Tizuco Morchida. Jogos infantis: o jogo, a criança e a educação. Petrópolis, RJ: Ed. Vozes, 1993.

MACHADO, N. J. Matemática e Educação: alegorias, tecnologias e temas afins. 2.ed. São Paulo: Cortez, 1995. 120 p.

PASCHOAL, Jaqueline Delgado; MACHADO, Maria Cristina Gomes. Imagens da Infância na Modernidade: da infância que temos à infância que queremos In: MORENO, Gilmara Lupion; AQUINO, Olga Ribeiro de; PASCHOAL, Jaqueline Delgado. Trabalho pedagógico na educação infantil. Londrina: Humanidades, 2007. p. 19, 20, 55 e 57.

PIAGET, Jean. A formação do símbolo na criança: imitação, jogo e sonho, imagens e representação. Rio de Janeiro: Guanabara, 1998.

\section{plurais}


PIAGET, J. Seis estudos de psicologia. Rio de Janeiro: Forense, 1980.

PILETTI, Claudinho. Didática geral. São Paulo: Ática, 1995.

PEDROSO, C de A. et al. Papel do brinquedo no desenvolvimento infantil. Faculdades Integradas do Vale do Ribeira. SCELISUL. 2011. Disponível em: www.scelisul.com.br/cursos/ graduacao/pd/artigo2.pdf. Acesso em: 16/06/2015.

SILVA. Ezequiel T. da. O professor e o combate à alienação imposta. $2^{\mathrm{a}}$ ed. São Paulo: Cortez: Autores Associados, 1991, p. 32 - 36.

TARDIF, M. Saberes docentes e formação profissional. Petrópolis, RJ: Vozes, 2002.

VIGOTSKI, L. S. Do Acto ao Pensamento. Lisboa: Morais, 1979.

VIGOTSKI, L.S. A Formação Social da Mente. $6^{\text {a }}$ ed. São Paulo, SP. Martins Fontes Editora LTDA, 1984.

VIGOTSKI, L.S. A construção do pensamento e da linguagem. São Paulo: Martins Fontes, 2001.

Recebido em: 30 de novembro de 2019.

Inserido em: 15 de outubro de 2020.

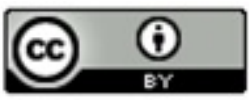

Esta obra está licenciada com uma Licença Creative Commons Atribuição 4.0 Internacional 